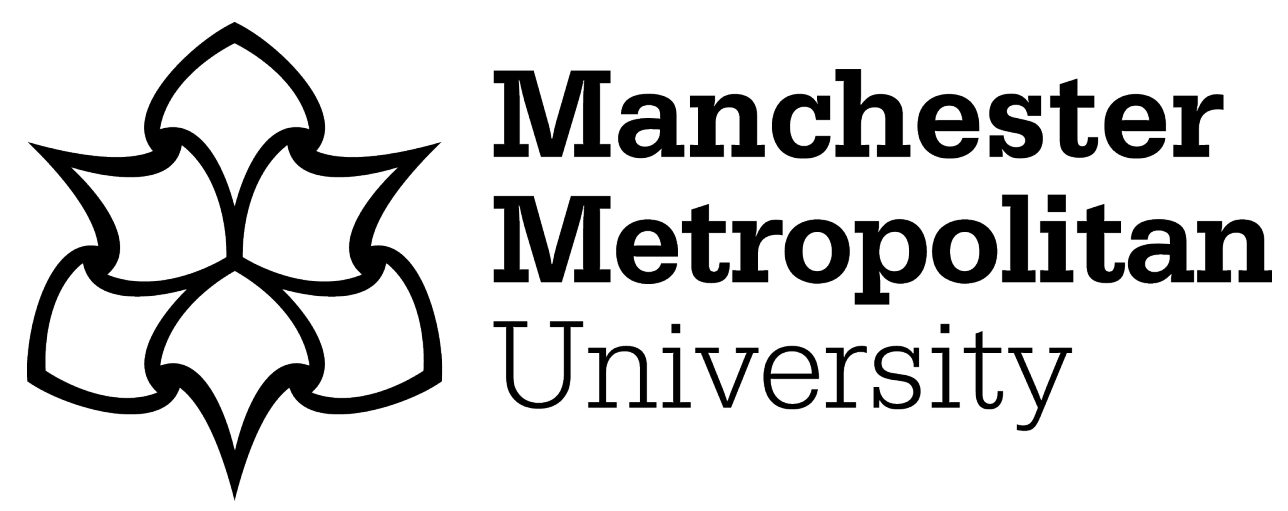

Dao, Phung ORCID logoORCID: https://orcid.org/0000-0002-8612-5589, Nguyen, Mai ORCID logoORCID: https://orcid.org/0000-0003-1276-8589 and Iwashita, Noriko (2021) Teachers' perceptions of learner engagement in L2 classroom task-based interaction. The Language Learning Journal, 49 (6). pp. 711-724. ISSN 0169-2046

Downloaded from: https://e-space.mmu.ac.uk/623863/

Version: Accepted Version

Publisher: Taylor \& Francis

DOI: https://doi.org/10.1080/09571736.2019.1666908

Usage rights: Creative Commons: Attribution-Noncommercial 4.0

Please cite the published version 
Dao, P., Nguyen, M. \& Iwashita (in press, 2019). Teachers' perceptions of learner engagement in L2 classroom task-based interaction.The Language Learning Journal DOI 10.1080/09571736.2019.1666908

\title{
Teachers' Perceptions of Learner Engagement in L2 Classroom Task-Based Interaction
}

\begin{abstract}
This study explored teachers' perceptions of learner engagement in L2 task-based interaction. Fifty-four pre- and in-service ESL/EFL teachers with different L1 backgrounds and L2 teaching experiences were asked to define and rate learner engagement in two learnerlearner interactions. The results revealed three major indicators that the teachers relied on in order to evaluate learner engagement. They included learners' level of deep thinking and attention to their partner's ideas, amount of content production, and level of interactiveness (e.g., amount of interaction and assistance). Only a small number of participants relied on learners' enthusiasm and positive attitudes in interaction, perceived as emotional engagement, to judge the learner engagement level. The results are discussed in terms of similarities and differences between L2 teachers and researchers in conceptualising the construct of learner engagement. The study also provides pedagogical implications regarding assessing learner engagement when implementing classroom peer interaction and suggests guidelines for promoting teachers' generation of L2 theories in teacher education courses.
\end{abstract}

Keywords: learner engagement, L2 task-based interaction, teachers' perceptions, L2 learning, teacher education 
Dao, P., Nguyen, M. \& Iwashita (in press, 2019). Teachers' perceptions of learner engagement in L2 classroom task-based interaction.The Language Learning Journal DOI 10.1080/09571736.2019.1666908

\section{Introduction}

A growing body of research has investigated various aspects of Task-Based Language Teaching (TBLT) as a leading pedagogical approach to second language (L2) learning (Long, 2015; Mackey, 2007; Ziegler, 2016). One of the major foci of TBLT research is to manipulate task features and task implementation to promote conversational adjustments that are considered central to L2 development (i.e., input modification, interactional feedback, noticing of language gaps and holes, and output production) (Long, 2015). Results of this research have shown the efficacy of tasks in supporting and facilitating L2 learning (see Dao \& McDonough, 2017; Dao \& McDonough 2018; Bygate, Skehan and Swain, 2001; Mackey, 2007). Alongside attention to task characteristics and implementation condition, L2 research has recently begun to investigate individual differences that are likely to affect the process and outcome of TBLT implementation, including learner engagement in tasks.

In L2 classrooms, one of teachers' frequent concerns is how to engage learners in classroom activities. The general assumption is that learners' high engagement in L2 taskbased interactions is likely to result in greater learning outcomes (Philp and Duchesne, 2016; Storch, 2008). Thus, L2 teachers have attempted to promote learner engagement in classroom activities through different pedagogical strategies. These include modelling (Kim and McDonough, 2011), training learners on using different interactional strategies (Fuji, Ziegler and Mackey, 2016; Sato and Lyster, 2012), and manipulating task features (Baralt, Gurzynski-Weiss, and Kim, 2016; Lambert, Philp and Nakamura, 2017) and task implementation (Dao \& McDonough, 2018; Qiu and Lo, 2017).

Despite being a commonly used term, what learner engagement actually refers to is still under discussion. Previous studies have conceptualised and operationalised learner engagement differently, such as the amount of language produced during task performance (Dörnyei and Kormos, 2000), effort in completing a task (Bygate and Samuda, 2009), or the 
Dao, P., Nguyen, M. \& Iwashita (in press, 2019). Teachers' perceptions of learner engagement in L2 classroom task-based interaction.The Language Learning Journal DOI 10.1080/09571736.2019.1666908

extent to which learners talk explicitly about language features (Storch, 2008). Recent studies have, additionally, conceptualised it as a multifaceted construct manifesting cognitive, social, emotional and behavioural dimensions (Dao \& McDonough, 2018; Baralt et al., 2016; Lambert et al., 2017; Qiu and Lo, 2017). This inconsistency in conceptualising learner engagement could be due to the top-down approach toward understanding the construct. In other words, researchers have tended to adopt a preconceived theoretical framework of learner engagement to serve their research purpose. Thus, it would be complementary to conceptualise this construct from a bottom-up approach by exploring L2 teachers' perceptions of learner engagement. Since L2 teachers are often expected to purposefully promote learner engagement in classroom task-based interaction, it is important to understand how they perceive learner engagement. In addition, previous research has suggested that offering teachers an opportunity to conceptualise and generate their own ideas and theories of L2 constructs is a beneficial practice. It enables L2 teachers to not only contribute to the validity and comprehensiveness of the conceptualisation of L2 constructs but also translate their own professional theories into their teaching practices (see Borg, 1999; Dogancay-Aktuna and Hardman, 2012). Thus, the current study aims to provide pre- and in-service L2 teachers an opportunity to conceptualise learner engagement and specify the indicators that they use to evaluate degrees of learner engagement as they observed episodes of learner-learner interactions.

\section{Learner Engagement in Task-Based Interaction}

Early L2 research often looked at learner engagement from a single dimension, including behavioural and/or cognitive aspects. Learner engagement was associated with various indicators, including the amount of language production (Dörnyei and Kormos, 2000); level of attention, that is, their meta-talk about language features (Storch, 2008); or effort to work with peers to communicate successfully and fulfil task goals (Bygate and 
Dao, P., Nguyen, M. \& Iwashita (in press, 2019). Teachers' perceptions of learner engagement in L2 classroom task-based interaction.The Language Learning Journal DOI 10.1080/09571736.2019.1666908

Samuda, 2009). Recently, L2 research has recognised the multidimensional characteristics of learner engagement (Dao, 2019; Philp and Duchesne, 2016; Svalberg, 2009; Svalberg 2017).

In the context of L2 task-based interaction, learner engagement is therefore defined as 'a state of heightened attention and involvement, in which participation is reflected not only in the cognitive dimension, but in social, behavioural and affective dimensions' (Philp and Duchesne, 2016, p. 51).

Cognitive engagement is often associated with learners' attention and mental effort (Helme and Clarke, 2001; Philp and Duchesne, 2016), alertness (Svalberg, 2009), and noticing or discussion of language features (Baralt et al., 2016; Storch, 2008; Toth, Wagner, and Moranski, 2013), as demonstrated in language-related episodes or LREs (i.e., discussion of language forms), negotiation of meaning, elaborative talk (e.g., talk used to clarify and expand semantic meanings), and idea units (e.g., amount of ideas or content) (Dao \& McDonough, 2018, 2019; Lambert et al., 2017; Phung, 2017; Qiu and Lo, 2017). Behavioural engagement is perceived as learners' time on task or participation, operationalised as, for example, language production (e.g., amount of time on task, and numbers of utterances, turns, and/or words). Social engagement highlights interactiveness and the relationship between learners in interaction, as reflected in learners' mutuality and reciprocity, affiliation, willingness to interact with peers, supportiveness, scaffolding, and assistance (Baralt et al., 2016; Storch, 2001). Backchannels, responsiveness, and episodes of task-related assistance are also frequent measures of social engagement (Dao \& McDonough, 2018; Lambert et al., 2017; Phung, 2017). Finally, emotional engagement usually refers to affective aspects, such as learners' feelings, motivation, willingness to communicate, and positive and negative attitudes during task performance (Baralt et al., 2017; Philp and Duschesne, 2016).

Studies that employed the framework of learner engagement as a multidimensional construct (Philp and Duchesne, 2016; Svalberg, 2009) have shown factors affecting learner 
Dao, P., Nguyen, M. \& Iwashita (in press, 2019). Teachers' perceptions of learner engagement in L2 classroom task-based interaction.The Language Learning Journal DOI 10.1080/09571736.2019.1666908

engagement in task performance. Specifically, tasks with a higher degree of complexity promoted greater cognitive, social and affective engagement; also, the degree of engagement was mediated by task environment, such as face-to-face versus online interaction (Baralt et al., 2016). Regarding task design, previous research showed that tasks requiring learners to generate their own content were more effective in motivating them to engage cognitively, behaviourally, socially and emotionally in task performance than tasks with teacher-generated content (Lambert et al., 2017). In addition, task with familiar topics promoted greater cognitive and behavioural engagement (Qiu and Lo, 2017), but repeating the tasks and selecting types of tasks that learners were less interested in decreased their level of engagement (Phung, 2017; Qiu and Lo, 2017). Task goals (convergent versus divergent) have also been shown to affect the extent to which the learners engage in the task-based interaction (Dao, 2019). While a convergent task goal induced learner's greater cognitive and social engagement, a divergent task goal decreased their level of engagement. The degree of learner engagement was also influenced by interlocutor proficiency, with learners showing greater cognitive and social engagement in interaction with a higher-proficiency partner than with a less proficient peer (Dao \& McDonough, 2018).

Despite adopting a similar framework for investigating learner engagement, existing research has also revealed discrepancies in how they operationalised the dimensions of learner engagement. For instance, each dimension is linked to different L2 concepts. Description of cognitive engagement is often related to attention, alertness, or LREs, whereas concepts such as mutuality, reciprocal, affiliation, or scaffolding are used to indicate social engagement. Similarly, emotional engagement reflects various affective aspects including different types of emotions (both negative and positive). Consequently, depending on the research purpose and the context, different measures were devised to capture these four types of engagement. This variation in the conceptualisation and measurement of learner engagement could be ascribed 
Dao, P., Nguyen, M. \& Iwashita (in press, 2019). Teachers' perceptions of learner engagement in L2 classroom task-based interaction.The Language Learning Journal DOI 10.1080/09571736.2019.1666908

to the top-down approach in which researchers imposed an overarching framework and measurements to assess learner engagement. Because learner engagement is a construct directly related to learners' performance in learning tasks administered by teachers, it is important to understand how teachers perceive it. Eliciting teachers' perceptions would inform researchers of specific aspects and types of learner engagement that teachers often pay attention to. This would help enhance our understanding of the construct and reveal indicators of learner engagement in task-based interaction that teachers are more likely to focus on. This practice is in line with the increasing trend in language teacher education to encourage teachers to generating L2 teaching and learning theories (Borgs, 1999; 2014; Burns, Freeman, and Edwards, 2015; Johnson and Golombek, 2016).

\section{Teachers' Involvement in Theorising Second Language Learning Concepts}

For complex constructs such as learner engagement, examining how L2 teachers perceive learner engagement based on their own L2 teaching experiences and/or practical perspective brings about several benefits. First, it adds more validity and comprehensiveness to conceptualising the construct through comparison of teachers' personal theories (i.e., theories generated by teachers/practitioners) and professional theories (i.e., theories proposed by experts/researchers) (see Borg, 1999; Dogancay-Aktuna and Hardman, 2012; O’Hanlon, 1993). Additionally, generating teachers' ideas is an effective way for teachers to link and translate professional theories into their teaching practices, which is one of the ultimate goals of $\mathrm{L} 2$ research. Third, this practice places teachers at the centre of the act of teaching, thus enhancing their autonomy. It may also help them to become more open toward scientific research, and promotes their engagement in research (Borg, 2006; Borg, 2010).

To sum up, a review of the literature shows that little is known about the extent to which L2 teachers' perceptions of learner engagement during task-based interaction align with and/or deviate from that of experts or researchers. Understanding teachers' perceptions 
Dao, P., Nguyen, M. \& Iwashita (in press, 2019). Teachers' perceptions of learner engagement in L2 classroom task-based interaction.The Language Learning Journal DOI 10.1080/09571736.2019.1666908

of learner engagement is important because it would help complement and refine the current frameworks of learner engagement that have been proposed by recent research (Philp and Duschene, 2016; Svalberg, 2009; Svalberg, 2017). In addition, despite scholarly attempts that advocated for encouraging language teachers to generate their own theories based on their teaching and learning experiences, there is a lack of empirical research that documents how L2 teachers might be guided to do so. These warrant the need to conduct further research in this area.

\section{Research Questions}

To explore teachers' perceptions of learner engagement in L2 task-based interaction, the study addresses the following questions.

1. What are the dimensions of learner engagement that L2 teachers focus on when evaluating degrees of learner engagement?

2. What is the teachers' definition of learner engagement in L2 classroom task-based interaction?

\section{Method}

\section{Participants}

The participants were fifty-four pre-service and in-service EFL/ESL teachers (11 males, 43 females), with a mean age of $25.94(S D=3.98)$. They came from different language backgrounds and nationalities: Chinese (30), Australian, (6), Vietnamese (5), Japanese (3), Indonesian (3), Chilean (2), and Malaysian, Korean, Singaporean, Iranian, and Brazilian (1 each). One participant had a Master's degree in Applied Linguistics, and four held a BA or a certificate in English language teaching; the rest had a BA in other majors such as Economics, Business, and Hospitality. At the time of data collection, fifty-one out of fifty-four participants were being enrolled in a Master's program in Applied Linguistics at an Australian university. The in-service teachers $(n=34)$ had a wide range of English teaching experience, 
Dao, P., Nguyen, M. \& Iwashita (in press, 2019). Teachers' perceptions of learner engagement in L2 classroom task-based interaction.The Language Learning Journal DOI 10.1080/09571736.2019.1666908

ranging from 3 months to 18 years $(M=3.29, S D=4.77)$. They had taught EFL/ESL at different levels and in diverse teaching contexts, mostly in Asian countries (32.35\% at university level; $23.53 \%$ at junior and high school; and the rest at primary level and private language centres). Although the pre-service teachers $(n=20)$ did not have experience teaching English to large groups of students, they $(n=5)$ reported to have had one-on-one tutoring experience $\left(M_{\text {year }}=.38, S D=.36\right)$.

\section{Design and Materials}

To facilitate the process of generating teachers' own theories of the construct of learner engagement, a three-stage task was designed following an inductive reasoning approach. This approach suggests that to generate new ideas without being influenced by previous theoretical frameworks, the task needs to provide experiential learning opportunities in which broad generalisations are drawn based on specific observations or experiences (Fernau, 2012; Neber, 2012; Seel, 2012). Thus, the first and second stage of the task were to give the participants an opportunity to undergo specific experiences (i.e., listening to the recordings, reading the transcripts, and rating intuitively the engagement levels of two episodes of peer interactions) before conducting an inductive reasoning process by generating original ideas of the construct learner engagement in the third stage (i.e., state their perceptions of learner engagement). Because the task was to elicit teachers' own perceptions about learner engagement, the concept of learner engagement was not explained to them before the implementation of the activity. The participants were also not required to complete any reading materials related to the topic of learner engagement before carrying out the task.

In Stage 1 of the three-stage task, the participants listened to the recordings of two interactions generated by two different pairs of EFL students. To aid the participants in judging the level of learner engagement in peer interactions, transcripts of the two episodes of peer interaction were also provided and the students were asked to read them before the 
Dao, P., Nguyen, M. \& Iwashita (in press, 2019). Teachers' perceptions of learner engagement in L2 classroom task-based interaction.The Language Learning Journal DOI 10.1080/09571736.2019.1666908

rating. In Stage 2, the participants intuitively rated the degree of each learner's engagement by indicating whether it was high, medium or low. The simple scale (high-medium-low) was used because it only served as a trigger activity that aims to provide the teachers with a stimulator to reflect on their experience of observing peer interaction and generating their original ideas of the definition and indicators of learner engagement. In addition, when evaluating the degree of learner engagement, it was stressed that the participants had to perceive themselves as a teacher. They also had to provide reasons for their rating decisions using a table provided in a handout. In Stage 3, they were asked to provide their own general definition and indicators of learner engagement based on their experience of previous ratings (see Appendix 1 for the task instruction and the table).

The materials also included two ten-minute recordings and two transcripts that were used in the three-stage task described above. The recordings and transcripts were taken from a larger project that investigated the relationship between learner engagement and L2 learning (Dao \& McDonough, 2017). The first recording and its transcript came from an interaction between two EFL university students who were asked to debate and discuss two shopping habits (shopping online versus in store). The second recording was generated by a different pair of EFL university students performing a task that asked them to discuss problems and solutions for their university (see Appendix 2 for task descriptions).

\section{Procedure}

The three-stage rating task was administered as a classroom activity in one of the participants' regularly scheduled classes. The course focused on exploring characteristics of L2 acquisition in the classroom context, and all the students reported that they had not read or been exposed to academic materials/readings about the concept of learner engagement prior to the class. For the particular session in which the rating task was delivered, the learning topic was 'Motivation and Engagement'. For participants who were not enrolled in this Master's 
Dao, P., Nguyen, M. \& Iwashita (in press, 2019). Teachers' perceptions of learner engagement in L2 classroom task-based interaction.The Language Learning Journal DOI 10.1080/09571736.2019.1666908

program $(n=3)$, they carried out the task in a separate session. The whole rating activity lasted for approximately 60 minutes. The participants listened to the first recording and read its transcript. Then, they rated the degrees of engagement of each learner in this pair and provided reasons for their rating decisions. The same procedure was repeated for the second pair. The participants then provided a definition of learner engagement in their own words and listed indicators of learner engagement.

\section{Analysis}

The participants' written responses were typed up and crosschecked. The data were then analysed by the first author following a thematic analysis approach (Braun and Clark, 2006; Dörnyei, 2007), which focuses on identifying recurrent patterns in the data. First, the data set was read through to locate segments in each participant's responses that were directly related to the key research inquiries (i.e., perceptions of learner engagement, reasons for engagement ratings). Second, codes were given to the highlighted segments based on key words and phrases identified in the segments. Finally, these initial codes were grouped into potential themes and clear names were created for each theme. The naming and grouping of themes were crosschecked with the second author, with all disagreements resolved through discussion. Frequency counts were conducted for each emerging coding category to show how frequently each key theme was repeated across participants.

\section{Results}

\section{Teachers' Ratings of Learner Engagement}

The first research question asked what specific aspects of learner engagement the teachers focused on when evaluating degrees of learner engagement. To address this research question, the participants were asked to rate the engagement level of each learner in two pairs and state specific reasons justifying their rating decisions. The results showed that despite being asked to rate levels of learner engagement intuitively on a three-point Likert scale (low, 
Dao, P., Nguyen, M. \& Iwashita (in press, 2019). Teachers' perceptions of learner engagement in L2 classroom task-based interaction.The Language Learning Journal DOI 10.1080/09571736.2019.1666908

medium, high) without any specific rating rubric, the rating results appeared to be consistent across participants regardless of whether they were pre- or in-service teachers. As presented in Table 1, the majority of the participants (77.78\%) attributed a high level of engagement to Learner 1, whereas $90.74 \%$ of participants rated the engagement level of Learner 2 as low. As for Learner 3 and 4, there was some variation in the ratings. While a majority $(59.26 \%$ and $61.11 \%$ ) rated them as highly engaged, one third of the participants stated that these learners had a medium level of engagement.

Table 1.

Teachers' ratings of learner engagement in language learning tasks

\begin{tabular}{lcccccccc}
\hline & \multicolumn{3}{c}{ Pair 1 } & \multicolumn{3}{c}{ Pair 2 } \\
\hline Engagement & Learner 1 & \multicolumn{3}{c}{ Learner 2 } & Learner 3 & \multicolumn{3}{c}{ Learner 4 } \\
& $n$ & $\%$ & $n$ & $\%$ & $n$ & $\%$ & $n$ & $\%$ \\
\hline Low & 1 & 1.85 & 49 & 90.74 & 3 & 5.56 & 5 & 9.26 \\
Medium & 11 & 20.37 & 4 & 7.41 & 19 & 35.19 & 16 & 29.63 \\
High & 42 & 77.78 & 1 & 1.85 & 32 & 59.26 & 33 & 61.11 \\
\hline
\end{tabular}

In addition, frequency counts revealed that there were consensuses or relative similarities between the pre- and in-service teachers in terms of their ratings of four learners (Table 2).

Table 2.

Pre- versus in-service teachers' ratings of learner engagement

\begin{tabular}{lcccccccc}
\hline \multirow{2}{*}{ Engagement } & \multicolumn{2}{c}{ Learner 1 } & \multicolumn{2}{c}{ Learner 2} & \multicolumn{2}{c}{ Learner 3 } & \multicolumn{2}{c}{ Learner 4 } \\
\cline { 2 - 8 } & $\begin{array}{c}\text { Pre- } \\
\text { service }\end{array}$ & $\begin{array}{c}\text { In- } \\
\text { service }\end{array}$ & $\begin{array}{c}\text { Pre- } \\
\text { service }\end{array}$ & $\begin{array}{c}\text { In- } \\
\text { Service }\end{array}$ & $\begin{array}{c}\text { Pre- } \\
\text { service }\end{array}$ & $\begin{array}{c}\text { In- } \\
\text { service }\end{array}$ & $\begin{array}{c}\text { Pre- } \\
\text { service }\end{array}$ & $\begin{array}{c}\text { In- } \\
\text { service }\end{array}$ \\
\hline \multirow{3}{*}{ Low } & $n(\%)$ & $n(\%)$ & $n(\%)$ & $n(\%)$ & $n(\%)$ & $n(\%)$ & $n(\%)$ & $n(\%)$ \\
Medium & $1(5)$ & $0(0)$ & $18(90)$ & $31(91)$ & $2(10)$ & $1(3)$ & $2(10)$ & $3(9)$ \\
High & $4(20)$ & $7(21)$ & $2(10)$ & $2(6)$ & $9(45)$ & $10(30)$ & $8(39)$ & $8(23)$ \\
\hline
\end{tabular}

Total: $n=20$ (pre-service), $n=34$ (in-service) 
Dao, P., Nguyen, M. \& Iwashita (in press, 2019). Teachers' perceptions of learner engagement in L2 classroom task-based interaction.The Language Learning Journal DOI 10.1080/09571736.2019.1666908

To explore the teachers' justifications behind their rating decisions, their written explanations were analysed. The results showed that they were essentially in agreement with each other in their rating reasons. Learner 1 was rated as highly engaged by a majority of the participants because his interaction exhibited three main characteristics. First, he showed a high level of deep thinking and attention to partner's ideas while participating in the task. Particularly, he appeared to engage with the topic of the task in a cognitively active manner by 'providing insightful reasons', 'attending to and building on partner's ideas', and 'initiating discussion on certain sub-topics and justifying his opinions'. Second, the teachers pointed out that this highly engaged learner made significant contribution to the task, as reflected in his production of task content or original ideas. In particular, he 'generated a lot of ideas to advance the conversation', and 'provided detailed and specified information'. Third, this learner demonstrated a high degree of interactiveness, perceived as amount of interaction and assistance, as shown in his persistence in 'prompting the partner', 'giving guidelines to the partner', 'providing many responses and feedback', and 'keeping the conversation going'.

Interestingly, for Learner 2 who was consistently rated as low in engagement, the reasons cited by the teachers were largely in contrast with those provided for the highly rated Learner 1. Specifically, Learner 2 showed a low level of deep thinking and attention to partner's ideas since 'she did not provide sufficient information to support her arguments and often produced irrelevant responses' and 'never responded to partner's ideas'. It is, therefore, not surprising that the teachers stated that this learner consequently contributed little to the task because she did not provide much content or relevant ideas. The participants noted that this low engaged learner 'didn’t have any input', 'provided very few ideas', 'superficially acknowledged, and only responded to the partner's question without initiation and offered no extra information'. Additionally, this learner appeared to have a low level of interactiveness. 
Dao, P., Nguyen, M. \& Iwashita (in press, 2019). Teachers' perceptions of learner engagement in L2 classroom task-based interaction.The Language Learning Journal DOI 10.1080/09571736.2019.1666908

Some evidence of this limited interactiveness was "she merely responded with simple 'yeah, uhm, and yes' and seldom expressed her opinions', and 'she just followed and repeated what the partner said and was not willing to contribute'. Another characteristic was that she tended to go off-task. Based on the teachers' observations, when her partner started to talk about the task, Learner 2 'just said something unrelated'. When it was her turn to talk, this learner was also "not focused on the task and made comments that were not relevant to the discussion topic'.

With regard to Learners 3 and 4, they were rated as highly engaged by the majority of the participants, but as moderately engaged by around one-third of the participants. For the majority of the teachers who rated Learners 3 and 4 as highly engaged, their reasons concerned the same three characteristics as reported for Learner 1 earlier: level of deep thinking and attention to partner's ideas, amount of content, and interactiveness. For those teachers who rated Learner 3 and 4 as moderately engaged learners, their reasons were that Learners 3 and 4 'did not contribute much to the conversation in the first part of task execution, but they became more active and showed more contribution later in the discussion'. Thus, the rating of Learners 3 and 4's engagement level as medium instead of high was because they 'were not active and did not contribute many ideas' in the first part of the conversation.

In summary, the teachers' reasons for determining learners' engagement level either as high, low, or medium, concerned largely two main aspects of interaction: cognitive aspect (i.e., level of deep thinking and attention to partner's ideas, and amount of relevant ideas or off-task ideas) and social aspect (i.e., interactiveness or amount of interaction and assistance).

\section{Teachers’ Perceptions of Learner Engagement}

The second research question asked how learner engagement in classroom peer interaction is defined by L2 teachers. Consistent with the themes identified in the teacher's 
Dao, P., Nguyen, M. \& Iwashita (in press, 2019). Teachers' perceptions of learner engagement in L2 classroom task-based interaction.The Language Learning Journal DOI 10.1080/09571736.2019.1666908

rating justifications, analyses of the teachers' self-generated definitions show three main recurrent themes that highlight how learner engagement was theorised following their observation and ratings of learner-learner interaction episodes.

The first and major theme was that learner engagement was defined as the extent to which learners show their deep thinking and attention to partner's opinions or ideas during the task, as identified by $96.29 \%(n=52)$ of the participants. They described this aspect of engagement using words such as high levels of 'development and advancement of the discussion', 'examination and exploration of the tasks to a high degree', 'depth of conversation', and 'attention to each other's ideas'.

In relation to the theme of level of deep thinking and attention to partner's ideas, the recurrent theme reported by $94.44 \%(n=51)$ of the participants as indicators of learner engagement was amount of content during the task discussion. Comments from the participants indicating this aspect as an indicator of learner engagement included 'amount of relevant content (i.e., opinions, ideas) produced during the interaction', 'amount of language or content production or talking time', and 'length of the conversation', and 'appropriateness and relevance of the opinions being exchanged'.

The third major emerging theme was level of interactiveness (e.g., amount of interaction and mutual assistance) between learners. Nearly $80 \%(n=43)$ of the participants shared this opinion, as reflected in the following comments: 'learners' mutual prompting and helping, and willingness to share thoughts during the interaction', 'level of initiation and mutual assistance', and 'frequency of opinion exchanges'.

Furthermore, task completion was also mentioned as an indicator of learner engagement. For instance, the following comments from $12.96 \%(n=7)$ of the participants demonstrated task completion as an indicator of engagement: 'degree of task completion', and 'individual effort and joint-effort in completing the task', 'taking it seriously to complete the 
Dao, P., Nguyen, M. \& Iwashita (in press, 2019). Teachers' perceptions of learner engagement in L2 classroom task-based interaction.The Language Learning Journal DOI 10.1080/09571736.2019.1666908

task', and 'learners' seriousness about completing the task'. Finally, although stated by only $16.6 \%(n=9)$ of the participants, learners' level of enthusiasm and positive attitude was considered as another indicator of engagement, as reflected in the following quotes: 'level of enthusiasm and energy displayed during the interaction', 'motivation and desire to carry out the task', and 'positive attitude to the task and the tone of speaking'. However, it should be noted that only a small number of the participants perceived task completion and level of enthusiasm and positive attitude as indicators of learner engagement.

To summarize, the data showed that L2 teachers defined and/or described learner engagement according to three major descriptors: (1) degree of deep thinking and attention to partner's ideas, (2) amount of content, and (3) level of interaction and assistance. These descriptors were clearly reflected in their justifications for the rating decisions. They could also be classified into two broad categories: cognitive (e.g., level of deep thinking and attention to partner's ideas, and amount of content production) and social (e.g., amount of interaction and assistance). Additionally, since task completion and level of enthusiasm and positive attitudes were perceived as indicators of learner engagement by only a small number of the participants, they did not seem to be main descriptors of learner engagement. Finally, the rating results showed that the teachers relied on salient features of each interaction as additional factors to judge learner engagement levels. For example, they cited off-task or irrelevant ideas in Learner 2 and less contribution of original ideas from Learners 3 and 4 in the first part of their interaction as descriptors of engagement.

\section{Discussion}

\section{Teachers' Generation of L2 Theories}

The goal of this study was to investigate pre- and in-service teachers' perceptions of learner engagement in L2 task-based interaction. The results show that the teachers perceived learner engagement as the extent to which they showed degrees of deep thinking and attention 
Dao, P., Nguyen, M. \& Iwashita (in press, 2019). Teachers' perceptions of learner engagement in L2 classroom task-based interaction.The Language Learning Journal DOI 10.1080/09571736.2019.1666908

to partner's ideas, production of content or ideas, and amount of interaction and assistance.

These perceptions of learner engagement cover two main dimensions of interaction: cognitive and social aspects. For instance, cognitive engagement could be seen through learners' degree of deep thinking and attention to partner's ideas, and amount of content or ideas; whereas social engagement can be referred to as learner's amount of interaction and assistance. These results corroborate the argument that learner engagement is a multifaceted construct (Philp and Duchesne, 2016; Svalberg, 2009; Svalberg 2017; Wang and Eccles, 2013). More importantly, they suggest a relative match between teachers' and research/experts' theories or framework of learner engagement, especially in relation to cognitive and social aspects (see Dao \& McDonough 2018; Dao \& McDonough 2019; Philp and Duchesne, 2016). This provides valuable empirical support for the viewpoint that language teachers are capable of constructing L2 learning theories, and should be encouraged to do so on a more frequent basis within teacher education courses (Kumaravadivelu, 2012; O’Hanlon, 1993).

\section{The Two Major Dimensions of Learner Engagement}

As reported earlier, the teachers predominantly perceived learner engagement as the extent to which they showed high level of deep thinking and attention to partner's ideas, produced content, and sustained interaction and/or provided assistance, which corresponds to cognitive and social engagement. These results indicate that cognitive and social aspects are what seem to be the major factors used by L2 teacher participants of this study when observing learner engagement. The other aspect as in the case of emotional engagement is limitedly observable. Thus, teachers' perceptions of learner engagement are not entirely compatible with the theoretical frameworks proposed by researchers who suggest learner engagement reflects four dimensions: cognitive, social, behavioural and emotional (Lambert et al., 2017; Philp and Duchesne, 2016). In addition, recent research suggests that it might not be legitimate to consider behavioural engagement as a separate dimension of learner 
Dao, P., Nguyen, M. \& Iwashita (in press, 2019). Teachers' perceptions of learner engagement in L2 classroom task-based interaction.The Language Learning Journal DOI 10.1080/09571736.2019.1666908

engagement, because it is actually the reflection of cognitive, social and emotional engagement (Dao \& McDonough, 2018; Dao \& McDonough 2019; Oga-Baldwin and Nakata, 2017; also see Reeve, 2012). The engagement rating results of the present study seem to be in line with this premise, as the teacher participants did not focus on behavioural engagement (e.g., number of words produced in interaction) (Lambert et al, 2017; Phung, 2017) as an indicator of learner engagement.

Furthermore, the emotional dimension of learner engagement did not seem noticeable to the teachers unless the learners explicitly showed these emotions, as shown in their enthusiasm level and positive attitudes towards the task. Even so, these factors were not described as main indicators of learner engagement by the majority of the teachers. These results suggest a partial mismatch between teachers and researchers in terms of considering emotional engagement as part of the construct learner engagement. This partial mismatch could be because emotions are often not easily detected in interaction since learners could conceal their actual emotions. Thus, an interesting question is whether teachers should be encouraged to pay attention to the emotional aspect of learner engagement or whether emotions should be excluded from the framework of learner engagement. Previous research showed that emotions affected learners' interaction (Skinner, Kindermann and Furrer, 2009; Swain, 2013). Therefore, it is legitimate to include emotional engagement as an aspect of learner engagement and to encourage teachers to take into consideration emotional aspects of learners in interaction. Also, one may argue that since the teachers of this study did not watch the interactions (i.e., they only listened to audio recordings and read the transcript), it might have been hard for them to pay attention to the learners' emotions. In fact, $16.6 \%$ of these teachers still reported that they could observe emotions by hearing learners' intonation and excitement (e.g., laughter). This legitimately rules out the impact of the lack of visual access on teachers' engagement ratings. 
Dao, P., Nguyen, M. \& Iwashita (in press, 2019). Teachers' perceptions of learner engagement in L2 classroom task-based interaction.The Language Learning Journal DOI 10.1080/09571736.2019.1666908

\section{Features of Learner Engagement Salient to Teachers}

The teachers' ratings of learner engagement also indicated that although drawing on similar criteria (e.g., level of deep thinking and attention to partner's ideas, amount of content production, and degree of interactiveness), the teachers tended to focus on specific or salient features of each interaction to evaluate learner engagement. For instance, the major reason for determining the high engagement level of Learner 1 was related to interaction aspect (i.e., amount of interaction, assistance, activeness in initiating and sustaining the conversation), as opposed to other dimensions of learner engagement (e.g., degree of deep thinking and attention to partner's ideas). In addition, when rating the engagement level of Learner 2, the most noticeable feature that drew the teachers' attention was her off-task behaviour, passiveness and negative emotions in interaction. As for Learner 4, the teachers pointed out that her limited contribution at the beginning of the interaction was one of their reasons for rating her engagement level as 'medium' instead of 'high', although she became more active and showed greater task contribution later in the interaction. These results suggest that one of the salient features of Learner 4's engagement is that it could fluctuate throughout the process of interaction, which resonates with the claim that interactional patterns are subject to change during task execution (Dao \& McDonough, 2017; Storch, 2001).

\section{Indicators and Measures of Learner Engagement}

It should be noted that indicators used by the teachers to identify the level of cognitive engagement included degree of deep thinking and attention to partner's ideas and amount of content. Previous engagement research used idea units (Dao \& McDonough, 2018; Dao, 2019; also see Shin, Lidster, Sabraw, and Yeager, 2016), language-related episode or LREs (i.e., discussion of language form) (Dao, 2019; Baralt et al., 2016), and negotiation for meaning (Philp et al., 2017) as measures of cognitive engagement. It appears that only idea units tape into one aspect of learner engagement (i.e. amount of content) identified by the 
Dao, P., Nguyen, M. \& Iwashita (in press, 2019). Teachers' perceptions of learner engagement in L2 classroom task-based interaction.The Language Learning Journal DOI 10.1080/09571736.2019.1666908

teacher. Measures have not yet been devised to gauge learners' level of deep thinking and attention to partner's ideas. Thus, it is suggested that learner's degree of deep thinking could be added as a measurement of cognitive engagement, operationalised as evaluative and elaborated comments, or talk episodes in which learners justify, reason, question, evaluate and negotiate their ideas or opinions (Helme and Clarke, 2001). Measures of attention to partner's ideas could include talk episodes where the learners reflected or commented on their partner's previous ideas or utterances and/or learners' self-reports of attention.

One may argue that degree of deep thinking and attention to partner's ideas is interrelated with amount of content. While this is reasonable to a certain extent, it is necessary to emphasise that learners' higher level of deep thinking and attention to partner's ideas does not necessarily result in high production of content or ideas. Responses and rating justifications from learners showed that they differentiated these two aspects. For example, the teachers provided two separate reasons for justifying why Learner 1 had high level of cognitive engagement: 'she attended to all of his partner's ideas and think a lot' and 'she provided lots of ideas'. Thus, these two aspects (deep thinking and attention to partner's ideas and amount of content) could be treated as separate indicators and measures of learners' cognitive engagement.

In addition, one discrepancy between the teachers and researchers in terms of their perceptions of learners' cognitive engagement is that researchers have used LREs and interactional moves that involve negotiation of meaning as indicators of cognitive engagement (Dao, 2019; Lambert et al., 2017), whereas the teachers in the present study did not seem to focus on this language aspect. In this sense, researchers considered negotiation of form as cognitive engagement. However, what appeared to be salient to the teachers was the extent to which the learners produced content and original ideas as well as advanced their argument in their interaction rather than the degree of negotiation of form and/or attention to 
Dao, P., Nguyen, M. \& Iwashita (in press, 2019). Teachers' perceptions of learner engagement in L2 classroom task-based interaction.The Language Learning Journal DOI 10.1080/09571736.2019.1666908

language. This poses an interesting question of why the teachers focused more on production of content and ideas as well as degree of deep thinking and attention to partner's ideas as indicators of cognitive engagement, rather than language aspects. One reason for this could be because the participants of this study were not teachers of the class from which interaction data were collected. This might have explained why they did not pay much attention to students' linguistic performance. If they had been the instructional teachers, this might result in different ratings of engagement. This issue therefore deserves further investigation. For example, future research can carry out the same task with learner interaction data taken from participants' own classrooms.

\section{Teachers' Beliefs about Learner Engagement}

The results also showed that despite general consistency, there were variations in the teachers' rating decisions for Learners 3 and 4 . This implies that to a certain extent the teachers might have held different opinions about indicators of learner engagement. For example, when explaining her conceptualisation of learner engagement, one participant noted, 'Silence and passiveness do not always mean low engagement. Some learners, like me, need time to process information, so I usually listen first, and process the information before starting to speak or produce good ideas'. This response indicated that individual differences, as shown in the teachers' reflection of their own experience as a language learner, might influence how they looked at other factors apart from the main indicators of learner engagement as reported above. Thus, it seems that there were cases in which high engagement was not explicitly visible, suggesting that behavioural measures of cognitive, social and emotional engagement need to be supplemented with other non-behavioural measures (see Dao \& McDonough, 2018).

In addition, one could argue that the teachers' teaching experience (pre- versus inservice teachers) as another individual difference factor might have had impacts on their 
Dao, P., Nguyen, M. \& Iwashita (in press, 2019). Teachers' perceptions of learner engagement in L2 classroom task-based interaction.The Language Learning Journal DOI 10.1080/09571736.2019.1666908

rating decisions; however, the results indicated that both types of teachers did not show much variations in their rating decisions (see Table 1). Thus, it appears that teaching experience did not seem to affect their perceptions of learner engagement. However, it should be noted that this interpretation is tentative since because the study was not explicitly focused on exploring this factor and little data were elicited from the participants about the impacts of their teaching experience on their rating decisions, which therefore needs further research to confirm the results.

\section{Learner Engagement in Language Specific Versus General Learning Tasks}

The results showed that indicators of learner engagement and reasons for the rating decisions were not language specific. It is often assumed that language teachers pay more attention to learners' linguistic performance during task execution because the purpose of administering tasks is for learners to learn language form through meaningful interaction (Ellis, 2003; Ellis and Shintani, 2014). However, in this research the indicators that the teachers used to rate learner engagement (e.g., degree of deep thinking and attention to partner's ideas, amount of information exchange or content production) could be employed for evaluating learner engagement in any learning tasks, not necessarily a language task. This poses a question of whether a high level of learner engagement is directly related to development in different aspects of an L2. Educational research has reported that students' engagement at the level of school and classroom tasks positively correlated with academic achievements (Christenson et al., 2012; Fredricks, Blumenfeld, and Paris, 2004). However, there has been no identifiable L2 research that establishes this causal link between learners' engagement level and their L2 learning outcomes (see Philp and Duchesne, 2017; Baralt et al., 2016; Lambert et al., 2017). This therefore remains an issue that warrants further research; particularly, two questions worth investigating are what learner engagement means for L2 learning, and whether it is directly or indirectly linked to L2 learning achievements. 

engagement in L2 classroom task-based interaction.The Language Learning Journal DOI 10.1080/09571736.2019.1666908

\section{Implications}

The study provides some pedagogical implications for both L2 teachers in engaging learners in tasks and L2 teacher educators. First, when implementing tasks, apart from focusing on cognitive (e.g., degree of deep thinking and attention to partner's ideas and amount of content) and social engagement (e.g., interactiveness) teachers may need to be more attentive to the emotional aspect of learner engagement in order to guide learners on how to perform tasks effectively. Second, although it is feasible to observe learners' behaviour to determine levels of engagement, it is important to be aware that behaviours may not always adequately reflect how learners engage in tasks. For instance, silence, often interpreted as passiveness in interaction, may not necessarily be indicative of low engagement, as one teacher argued in her response. Thus, L2 teachers need to consider learners' individual differences (i.e., beliefs) when promoting their engagement in task interaction. Moreover, being aware of indicators of learner engagement such as degrees of deep thinking and attention to partner's ideas, amount of interaction and assistance, and enthusiasm or positive attitudes, teachers could use these indicators as a guideline for preparing, modelling and/or guiding learners on how to interact and engage well in tasks.

In addition, the study results, which show relative matches and nuanced discrepancies between how L2 teachers and researchers conceptualise learner engagement, speaks to the importance of guiding pre- and in-teachers to actively generate L2 learning theories during teacher education courses. This practice may include three steps, as described in the present study: (i) presenting student teachers with examples of authentic classroom tasks/situation to observe, (ii) asking them to critically analyse the situation from the lens of one teaching or learning theory/construct they need to learn, and (iii) guiding them to produce abstract conceptualisation/definition of the construct. This can help teachers make personal and 
Dao, P., Nguyen, M. \& Iwashita (in press, 2019). Teachers' perceptions of learner engagement in L2 classroom task-based interaction.The Language Learning Journal DOI 10.1080/09571736.2019.1666908

meaningful connection with L2 theories, thereby obtaining a better understanding and a clearer sense of how they may apply them to their teaching practice.

\section{Conclusion}

This study explored teachers' perceptions of learner engagement in L2 task-based interaction. The results showed that there were three major indicators that the teachers relied on in order to evaluate learner engagement: learners' level of deep thinking and attention to partner's ideas, amount of content, and amount of interaction and assistance, which corresponds to the cognitive and social aspects of learner engagement as conceptualised in the researchers' framework of learner engagement. Other factors specific to each interaction (e.g., off-task behaviour, or negative emotions) were only noticeable if learners appeared to demonstrate them repetitively. These results suggest a partial match between teachers and researchers in terms of the components of learner engagement, with teachers focusing largely on the cognitive and social aspect rather than the emotional and/or behavioural aspect of interaction. The results also suggest that teachers perceived learner engagement as multifaceted, supporting previous research that conceptualised learner engagement as a multidimensional construct, reflecting cognitive, social and emotional aspects. The findings also provide further insight into the construct of learner engagement in TBLT research and indicate specific aspects of learner engagement. Future research could therefore use the indicators suggested in this study to devise concrete measures for investigating learner engagement in tasks and employ in-depth interviews with L2 teachers to provide more insights into factors that impact on teachers' view of learner engagement.

\section{Notes:}

The authors confirm that there is no conflict of interest regarding this manuscript. There is no funding for the research project on which the manuscript is based. 
Dao, P., Nguyen, M. \& Iwashita (in press, 2019). Teachers' perceptions of learner engagement in L2 classroom task-based interaction.The Language Learning Journal DOI 10.1080/09571736.2019.1666908

\section{References}

Baralt M., Gurzynski-Weiss L., and Kim Y. (2016). Engagement with the language: How examining learners' affective and social engagement explains successful learnergenerated attention to form. In Sato M. and Ballinger S (Eds.) Peer interaction and second language learning: Pedagogical potential and research agenda. Amsterdam: John Benjamins, $209-239$.

Borg, S. (1999). Teachers' theories in grammar teaching. ELT Journal, 53: 157-167. doi.org/10.1093/eltj/53.3.157

Borg, S. (2006). The distinctive characteristics of foreign language teachers. Language Teaching Research, 10: 3-31.

Borg, S. (2010). Language teacher research engagement. Language teaching, 43: 391-429.

Borg, S. (2014). The benefits of attending ELT conferences. ELT Journal, 69: 35-46.

Brown, A. (2009) Students' and teachers' perceptions of effective foreign language teaching: a comparison of ideals. Modern Language Journal, 93: 46-60.

Burns A., Freeman D., and Edwards E. (2015). Theorizing and studying the languageteaching mind: Mapping research on language teacher cognition. Modern Language Journal, 99: 585-601.

Bygate M., and Samuda V. (2009) Creating pressure in task pedagogy: The joint roles of field, purpose, and engagement within the interaction approach. In Mackey A, Polio C (Eds.), Multiple perspectives on interaction: Second language research in honour of Susan M. Gass. New York, NY: Taylor and Francis/Routledge: 90-116.

Christenson S., Reschly A., and Wylie C. (2012) Handbook of research on student engagement. New York: Springer, 149-172.

Dao, P., \& McDonough, K. (2017). The effect of task role on Vietnamese EFL learners' collaboration in mixed proficiency dyads, System, 65, 15 -24. 
Dao, P., Nguyen, M. \& Iwashita (in press, 2019). Teachers' perceptions of learner engagement in L2 classroom task-based interaction.The Language Learning Journal DOI 10.1080/09571736.2019.1666908

Dao, P. \& McDonough (2018). Effect of proficiency on learner engagement. International Journal of Educational Research, 88, 60-72.

Dao, P. (2019). Effects of task goal orientation on learner engagement in task performance. International Review of Applied Linguistics in Language Teaching (IRAL). DOI: https://doi.org/10.1515/iral-2018-0188.

Dogancay-Aktuna S., and Hardman J. (2012). Teacher education for EIL: working toward a situational meta-praxis. In Matsuda A (Ed.), Principles and practice of teaching English as an international language. Bristol, UK: Multilingual Matters, 103-118.

Dörnyei Z., and Kormos J. (2000) The role of individual and social variables in oral task performance. Language Teaching Research 4: 275-300.

Ellis R., and Shintani N. (2014). Exploring Language Pedagogy through Second Language Acquisition Research. New York: Routledge.

Fredricks J., Blumenfeld P., and Paris A. (2004). School engagement: Potential of the concept, state of evidence. Review of Educational Research, 74: 59-105.

Fujii A., Ziegler N., and Mackey A. (2016). Peer interaction and metacognitive instruction in the EFL classroom. In Sato M,. and Ballinger S. (Eds.), Peer interaction and second language learning: Pedagogical potential and research agenda. Amsterdam: John Benjamins, $63-90$.

Helme S., and Clarke D. (2001) Identifying cognitive engagement in the Mathematics classroom. Mathematics Education Research Journal, 1:133-153.

Johnson K. E., and Golombek P. R. (2016). Mindful L2 teacher education: A sociocultural perspective on cultivating teachers' professional development. Routledge.

Kim Y., and McDonough K. (2011) Using pretask modelling to encourage collaborative learning opportunities. Language Teaching Research, 15:183-199. 
Dao, P., Nguyen, M. \& Iwashita (in press, 2019). Teachers' perceptions of learner engagement in L2 classroom task-based interaction.The Language Learning Journal DOI 10.1080/09571736.2019.1666908

Kumaravadivelu B. (2012). Language teacher education for a global society: A modular model for knowing, analyzing, recognizing, doing, and seeing. New York: Routledge.

Lambert C., Philp J., and Nakamura S. (2017) Learner-generated content and engagement in second language task performance. Language Teaching Research, 21: 665-680.

O'Hanlon C. (1993) The importance of an articulated personal theory of professional development. In Elliott J (Ed.), Reconstructing teacher education: Teacher development London: Falmer Press, 243-255.

Philp J., and Duchesne S. (2016). Exploring engagement in tasks in the language classroom. Annual Review of Applied Linguistics, 36: 50-72.

Philp J., and Mackey A. (2010). Interaction research: What can socially informed approaches offer to cognitivists (and vice versa)? In Batstone R (Ed.), Sociocognitive perspectives on language use and language learning. New York: Oxford University Press, 210 228.

Phung L. (2017). Task preference, affective response, and engagement in L2 use in a US university context. Language Teaching Research, 21: 751-766.

Qiu X., and Lo Y. (2017). Content familiarity, task repetition and Chinese EFL learners' engagement in second language use. Language Teaching Research, 21: 681-698.

Sato M., and Lyster R. (2012). Peer interaction and corrective feedback for accuracy and fluency development. Studies in Second Language Acquisition, 34: 591-626.

Storch N. (2001). How collaborative is pair work? ESL tertiary students composing in pairs. Language Teaching Research, 5: 29 -53.

Storch N. (2008). Metatalk in a pair work activity: Level of engagement and implications for language development. Language Awareness, 17: 95-114.

Svalberg A. (2009). Engagement with language: Interrogating a construct. Language Awareness, 18: 242-258. 
Dao, P., Nguyen, M. \& Iwashita (in press, 2019). Teachers' perceptions of learner engagement in L2 classroom task-based interaction.The Language Learning Journal DOI 10.1080/09571736.2019.1666908

Svalberg A. (2017). Researching language engagement; current trends and future directions. Language Awareness, Published online Nov 27, 2017.

Toth P., Wagner E., and Moranski K. (2013). Co-constructing' explicit L2 knowledge with high school Spanish learners through guided induction. Applied Linguistics, 34: 255278.

Eccles J., and Wang M. (2012). Part I commentary: So what is student engagement anyway? In Christenson S, Reschly A., and Wylie C. (Eds.), Handbook of research on student engagement. US: Springer, 133-145.

Wyatt M,. and Borg S. (2011). Development in the practical knowledge of language teachers: A comparative study of three teachers designing and using communicative tasks on an in-service BA TESOL programme in the Middle East. Innovation in Language Learning and Teaching, 5:233-252. 
Dao, P., Nguyen, M. \& Iwashita (in press, 2019). Teachers' perceptions of learner engagement in L2 classroom task-based interaction.The Language Learning Journal DOI 10.1080/09571736.2019.1666908

\section{Appendix 1}

\section{A three-stage task}

\section{Instructions: Rating learner engagement in tasks}

1. Listen to two ten-minute recordings and read transcripts of interactions between two students carrying out two tasks (see task description below).

2. Intuitively rate the level of learner engagement in the task from the language teacher's perspective by indicating whether learner engagement is 'high', 'medium' or 'low' for each learner.

3. Note down specific reasons explaining your rating decision. Identify features of interaction that you base on to determine learner engagement

4. After rating the interactions, write down a general definition of learner engagement in your own words based on the rating experience that you have done.

Note: Use your intuition as a language teacher in order to evaluate learner engagement.

Table for recording your answers

\begin{tabular}{|l|c|c|}
\hline Pair 1 & $\begin{array}{c}\text { Engagement level } \\
\text { (high, medium, low) }\end{array}$ & $\begin{array}{c}\text { Reasons for your rating decision } \\
\text { (At least three specific reasons) }\end{array}$ \\
\hline Whole pair & & \\
\hline Learner 1 & & \\
\hline Learner 2 & & \\
\hline
\end{tabular}

\begin{tabular}{|l|c|c|}
\hline Pair 2 & $\begin{array}{c}\text { Engagement level } \\
\text { (high, medium, low) }\end{array}$ & $\begin{array}{c}\text { Reasons for your rating decision } \\
\text { (At least three specific reasons) }\end{array}$ \\
\hline Whole pair & & \\
\hline Learner 1 & & \\
\hline Learner 2 & & \\
\hline
\end{tabular}

Your general definition and indicators of engagement in your own words after rating the interactions 
Dao, P., Nguyen, M. \& Iwashita (in press, 2019). Teachers' perceptions of learner 29 engagement in L2 classroom task-based interaction.The Language Learning Journal DOI 10.1080/09571736.2019.1666908 
Dao, P., Nguyen, M. \& Iwashita (in press, 2019). Teachers' perceptions of learner 30 engagement in L2 classroom task-based interaction.The Language Learning Journal DOI 10.1080/09571736.2019.1666908

\section{Appendix 2}

\section{The tasks}

Shopping task

- Work in pairs, debate/discuss about your preference (i.e., advantages and disadvantages) towards shopping online or shopping at the store. State reasons to argue for your opinions.

- At the end of the task, submit a list of reasons to explain your preference as well as reasons to argue against your partner. The lists will be used in order to write a report that evaluates students' shopping behaviour.

University task

- Work in pairs and discuss to identify problems existing in your university and propose solutions to these problems.

- At the end of the task, submit a list of problems and solutions that you agree on, which will be used later in order to write a report. 